EESTI NSV TEADUSTE AKADEEMIA TOIMETISED, 23. KOIDE KEEMIA * GEOLOOGIA. 1974, NR. 3

ИЗВЕСТИЯ АКАДЕМИИ НАУК ЭСТОНСКОИ ССР. ТОМ 23 ХИМИЯ * ГЕОЛОГИЯ. 1974, № 3

\title{
ВЛИЯНИЕ НЕКОТОРЫХ МИНЕРАЛЬНЫХ ПРИМЕСЕЙ НА СКОРОСТЬ БИООКИСЛЕНИЯ ФЕНОЛОВ
}

Одним из источников загрязнения среды и особенно водоемов являются сточные воды предприятий топливно-химической, в том числе сланцехимической, промышленности, в которых вырабатываются и используются фенолы разлинного строения. В общей схеме очистки вод, загрязненных фенолами, важное звено представляет процесс биохимического окисления токсичных веществ, изучение жинетики и механизма которого служит главным средством для повышения эффективности обесфеноливания промстока,

Из литературы $\left[{ }^{1-5}\right]$ известна возможность применения методов химической кинетики для изучения скорости биоокисления фенолов и их смесей на ряде адаптированных активных илов. Прн этом установлено, что процесс деградации фенолов сильно тормозится при окисленин их в составе смесей в условиях, в которых возможно отчетливое проявление антиокислительных свойств некоторых соединений этого класса, В сточных водах сланцевой промышленности наряду с фенолами присутствуют также м.неральные примеси, главным образом соли, в состав которых входят тиосульфат-анионы и хлор-ноны $\left[{ }^{6,7}\right]$. Их содержание колеблется в широких пределах в зависимости от типа агрегата и принятого режима переработки сланца.

Цель настоящего исследования заключалась поэтому в изучении возможного влияния указанных двух основных видов минеральных примесей на скорость биохимического окисления фенолов на адаптированных активных илах для выяснения факторов, снижающих эффективность бнологической очистки.

\section{Методика и объекты исследования}

Эксперимент проведен в лабораторном контактном аэротенке емкостью $1 \Omega$ с использованием активного ила из промышленной установки биоочистки СПК «Сланцы», предварительно подвергнутого соответствующей устойчивой адаптащии в течение 2-4 месяцев. Дозировка ила производилась из расчета 2-3 г сухого вещества на литр раствора, в котором исходное содержание фенолов составляло $200-500 \mathrm{~m} / \Omega$ в соответствии с их концентрацией в промышленном стоке [8, 9].

Для создания условий, обеопечивающих жизнедеятельность микроорганизмов, в приготовленные растворы фенолов добавлялись соли $\mathrm{K}_{2} \mathrm{HPO}_{4}$ и $\left(\mathrm{NH}_{4}\right)_{2} \mathrm{SO}_{4}$. Аэрация и перемешивание иловой смеси осуществлялись воздухом, который подавался в нижнюю часть аэротенка через стеклянный фильтр со скоростью $0,3-0,4 \Omega /$ мин, что, по данным [5], обеспечивает достаточное содержание растворенного кислорода в жидкости на уровне $5-7$ мг/л, 
В эксперименте использованы фенолы марки «ч» (табл. 1) без дополнительной их очистки, поскольку установлено [5], что наличие примесей, регламентированных маркой реактива, не оказывает влияния на кинетику биоокисления основных реагентов. Раствор фенола приготовлялся непосредственно перед опытом, пробы его отбирались из средней части аэротенка сразу после смешивания раствора с активным илом и далее через определенные интервалы времени, длительность которых определялась реакционной способностью данного фенола. Концентрация фенолов измерялась колориметрически с применением 4-аминоантипирина.

\section{таблица 1}

Константы скорости биохимического окисления фенолов $\left(k_{0} \cdot 10^{-5}\right.$ моль/ $\left.\Omega \cdot м u H\right)$, адаптированных к субстратам разного строения

\begin{tabular}{l|l|l|l}
\hline \multirow{2}{*}{ Фенол } & \multicolumn{3}{|c}{ Субстрат активного ила } \\
\cline { 2 - 4 } & Оксибензол & Резорцин & $\begin{array}{l}\text { Смесь фено- } \\
\text { лов из про- } \\
\text { изводстен- } \\
\text { ного стока }\end{array}$ \\
\hline
\end{tabular}

$\begin{array}{lccl}\text { Оксибензол } & 8,0 & 0,2 & 0,2 \\ \text { Резорцин } & 0,98 & 9,9 & 4,7 \\ \text { 5-Метилрезорцин } & 0,33 & 1,02 & 1,03 \\ \text { Пирокатехин } & 10,9 & 43,6 & 7,9\end{array}$

Минеральные примеси, включающие хлор-ионы и тиосульфат-анионы, вводились в систему в виде тиосульфата натрия и хлористого калия марки «ч». Содержание их варьировалось в пределах $50-500$ мг/л также в соответствии с их возможными пределами изменения содержания в фенольном стоке, поступаюшем на биофильтры [6,7].

Графическая обработка первичных результатов исследования показывает, что при совмещении на одном графике экспериментальных точек для нескольких параллельных опытов они могут быть соединены прямыми с близким углом наклона. Последние можно экстраполировать к одной и той же исходной концентрации (рис. 1). Правомерность такого методического приема установлена в работах $\left[{ }^{1-5}\right]$.

\section{Результаты исследования и их обсуждение}

В подавляющей части опытов изменение концентрации фенола во времени на основном участке протекает по линейному закону, что свидетельствует о нулевом порядке суммарной реакции окисления. Типичные кинетические кривые приведены на рис. 1 и в нашем предыдущем сообщений [10]. Несмотря на сложность процесса, протекающего под воздействием биологической системы, результаты эксперимента отличаются хорошей воспроизводимостью. Коэффициент корреляции при определении констант скоростей биоокисления достигает $0,94-0,99$. Значения констант скоростей определялись по обычному для формальной кинетики принципу, в случае линейной убыли концентрации фенола - по изменению этого показателя в единицу времени [111. В тех случаях, когда линейный характер снижения концентрации фенола в реакционной смеси нарушался, значения констант скорости определялись для начального линейного участка, в котором не отражалось искажающее влияние накопления промежуточных продуктов. 
Скорость биохимического окисления фенолов без минеральной п р и м ес и зависит от структуры фенола и субстрата, к которому устойчиво адаптирована данная система. Судя по значениям констант скорости (табл. 1), окисление изученных многоатомных фенолов про-

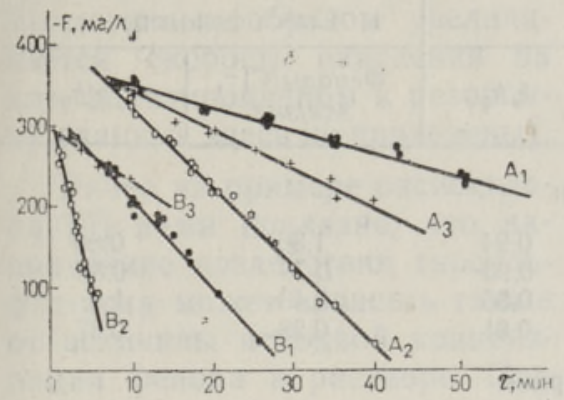

Рис. 1. Кинетика разложения резорцина $(A)$ и пирокатехина $(B)$ на активных илах с адаптацией к оксибензолу (1), резорцину (2) и промышленной смеси фенолов (3).

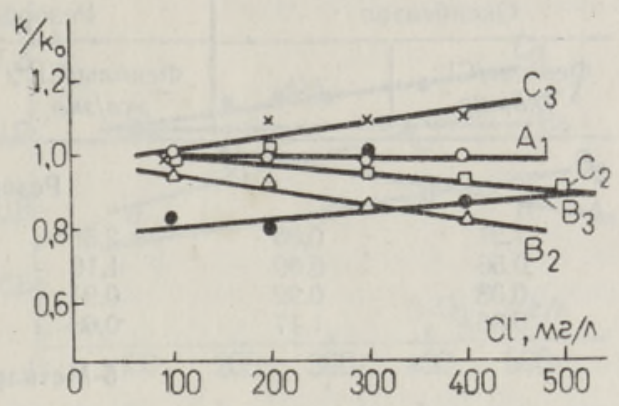

Рис. 2. Влияние хлор-аниона на скорость окисления оксибензола $(A)$, резорцина $(B)$ и 5-метилрезорцина $(C)$ на активных илах, адаптированных к оксибензолу (I), резорцину (2) и промышленной смеси фенолов (3).

исходит на всех субстратах, но с наибольшей скоростью на иле, адаптированном к резорцину. Отметим особую реакционную способность пирокатехина - наиболее вероятного промежуточного продукта окисления одноатомных фенолов $\left[{ }^{12-14}\right]$, который активно разлагается на всех трех системах, хотя абсолютные значения константы скорости его окисления определяются природой субстрата. Полученные результаты неплохо совпадают с данными Н. Берновской с сотр. $\left.{ }^{1-5}\right]$. Исключение составляет лишь высокая избирательность процесса деградации оксибензола, который протекает с пониженной интенсивностью на активных илах, адаптированных к резорцину и смеси фенолов из промышленного стока. Наиболее вероятной причиной этого явления может быть методика адаптации активного ила - в проточной системе вместо описанной в $[1-5]$, где использовался для этой цели контактный аэротенк со значительным перепадом концентрации реагирующего вещества.

Присутствие в растворе хлор-иона влечет за собой снижение скорости окисления резорцина в среднем на $10-20 \%$ почти независимо от характера субстрата (табл. 2, рис. 2). Аналогичная закономерность отмечается для деградации 5-метилрезорцина на активных илах, адаптированных к фенолу (в среднем 20\%) и резорцину (до 9\%). При этом наблюдается тенденция к увеличению тормозящего действия хлор-иона по мере повышения его концентрации в растворе. Противоположные результаты получены, однако, на иле, адаптированном к промышленной смеси фенолов: в этом случае отмечается, напротив, ускорение окисления 5-метилрезорцина - в среднем на $10 \%$ - (табл. 2, рис. 2) и пирокатехина. Разложение последнего ускоряется на иле, адаптированном к резорцину (данные здесь не приведены).

Напомним также, что, по [10], наличие хлор-иона не оказывает влияния на скорость разложения оксибензола, расхождение экспериментальных данных не выходит за пределы погрешности опыта. Эти сведения подтверждаются также опытами на других субстратах.

Таким образом, направление влияния хлор-иона, которое по изменению абсолютной величины показателей не превышает $20 \%$, зависит от 
Влияние добавки хлор-иона на скорость биоокисления резорцина и 5-метилрезорцина

\begin{tabular}{|c|c|c|c|c|c|}
\hline \multicolumn{2}{|c|}{ Оксибензол } & \multicolumn{2}{|c|}{ Резорцин } & \multicolumn{2}{|c|}{ Смесь фенолов } \\
\hline $\begin{array}{c}\text { Фенолы } / \mathrm{Cl}^{-} \text {, } \\
\text { экв/экв }\end{array}$ & $k / k_{0}$ & $\begin{array}{l}\text { Фенолы/Cl-, } \\
\text { экв/экв }\end{array}$ & $k / k_{0}$ & $\begin{array}{c}\text { Фенолы } / \mathrm{Cl}^{-} \text {, } \\
\text { экв/экв }\end{array}$ & $k / k_{0}$ \\
\hline \multicolumn{6}{|c|}{ Резорцин } \\
\hline $\begin{array}{l}1,21 \\
0,56 \\
0,38 \\
0,36\end{array}$ & $\begin{array}{l}0,85 \\
0,80 \\
0,92 \\
1,17\end{array}$ & $\begin{array}{l}2,58 \\
1,16 \\
0,91 \\
0,68\end{array}$ & $\begin{array}{l}0,94 \\
0,93 \\
0,85 \\
0,81\end{array}$ & $\begin{array}{l}1,36 \\
0,79 \\
0,43 \\
0,28\end{array}$ & $\begin{array}{l}0,86 \\
0,80 \\
1,0 \\
0,87\end{array}$ \\
\hline \multicolumn{6}{|c|}{ 5-Метилрезорцин } \\
\hline $\begin{array}{l}0,37 \\
0,34 \\
0,20 \\
0,11\end{array}$ & $\begin{array}{l}0,78 \\
0,80 \\
0,80 \\
0,29\end{array}$ & $\begin{array}{l}0,94 \\
0,50 \\
0,33 \\
0,24 \\
0,21\end{array}$ & $\begin{array}{l}1,0 \\
1,0 \\
0,96 \\
0,93 \\
0,91\end{array}$ & $\begin{array}{l}0,99 \\
0,59 \\
0,34 \\
0,26\end{array}$ & $\begin{array}{l}1,0 \\
1,08 \\
1,08 \\
1,11\end{array}$ \\
\hline
\end{tabular}

химической структуры реагента и субстрата, но не связано с величиной скорости разложения $\left(k_{0}\right)$ исследуемого фенола в данной системе.

Картина, сопровождающая ввод в систему добавки ти осульф а т а ни он а, также весьма сложна. Такая добавка снижает скорость биоокисления резорцина при условии адаптации активного ила к резорцину (на $7-30 \%$ ) и фенолу (на 5-20\%). При этом с увеличением концентрации мннеральной добавки тормозящее действие ее уменьшается (табл. 3, рис. 3). На скорости деградации резорцина вовсе

таблица 3

Влияние добавки тиосульфат-аниона на скорость биоокисления резорцина и 5-метилрезорцина

\begin{tabular}{|c|c|c|c|c|c|}
\hline \multicolumn{6}{|c|}{ Субстрат активного ила } \\
\hline \multicolumn{2}{|c|}{ Оксибензол } & \multicolumn{2}{|c|}{ Резорцин } & \multicolumn{2}{|c|}{ Смесь фенолов } \\
\hline $\begin{array}{c}\text { Фенолы } / \mathrm{S}_{2} \mathrm{O}_{3}{ }^{2-}, \\
\text { экв/экв }\end{array}$ & $k / k_{0}$ & $\begin{array}{c}\text { Фенолы } / \mathrm{S}_{2} \mathrm{O}_{3}{ }^{2-} \text {, } \\
\text { экв/экв }\end{array}$ & $k / k_{0}$ & $\begin{array}{c}\text { Фенолы } / \mathrm{S}_{2} \mathrm{O}_{3}{ }^{2-}, \\
\text { экв/эк } \theta\end{array}$ & $k / k_{0}$ \\
\hline
\end{tabular}

\begin{tabular}{llllll}
\multicolumn{5}{c}{ Резорцин } \\
1,78 & 0,74 & 3,2 & 0,70 & 2,17 & 1,0 \\
0,63 & 0,93 & 1,9 & 0,86 & 0,92 & 1,0 \\
0,58 & 0,82 & 1,27 & 0,78 & 0,62 & 1,0 \\
0,60 & 0,92 & 0,85 & 0,81 & 0,44 & 1,0 \\
& & 0,69 & 0,86 & & \\
& \multicolumn{5}{c}{$\mathbf{5}$-Метилрезорцин } \\
0,60 & 0,86 & 1,51 & 0,78 & 1,65 & 1,0 \\
0,55 & 0,78 & 0,71 & 0,90 & 0,97 & 1,08 \\
0,31 & 0,72 & 0,53 & 0,99 & 0,50 & 1,08 \\
0,19 & 0,29 & 0,37 & 0,95 & 0,42 & 1,11 \\
& & 0,33 & 1,0 & &
\end{tabular}

не отражается добавка тиосульфата при использовании ила, адаптированного к смеси фенолов из промышленного стока. Скорость окисле- 
ния снижается также при деградации 5-метилрезорцина на активных илах при их адаптации к фенолу (на 20-30\%) или резорцину (до 20\%); см. табл. 3 и рис. 3 . Однако те же добавки ускоряют (до 12\%) биоокисление 5-метилрезорцина в случае адаптации ила к промышленной смеси фенолов (табл. 3, рис. 3). Аналогичным образом увеличивается скорость окисления на иле, адаптированном к резорцину (данные здесь не приведены).

Ранее на примере оксибензола [10] нами показано, что направление воздействия тиосульфат-иона может зависеть также от величины исходной концентрации фенола в растворе. При небольшом его содержании (до 300 мг/ $\Omega$ ) наличие этой минеральной примеси ускоряет, а при высокой концентрации основного реагента (более $400 \mathrm{~m} / \Omega$ ) - замедляет процесс окисления.

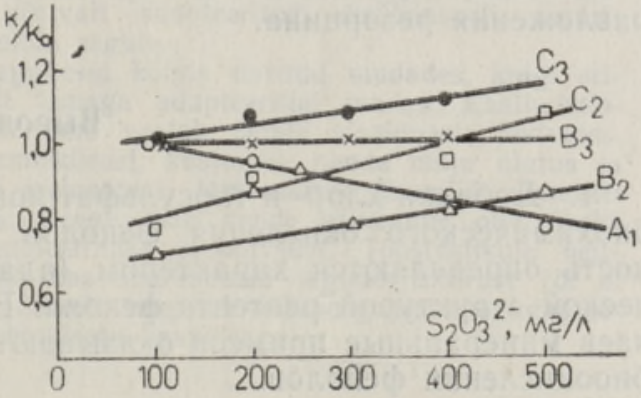

Рис. 3. Влияние тиосульфат-аниона на скорость окисления оксибензола $(A)$, резорцина $(B)$ и 5-метилрезорцина $(C)$ на активных илах, адаптированных к оксибензолу (I), резорцину (2) и промышленной смеси фенолов (3).

Из приведенного следует, что добавка тиосульфат-аниона вызывает снижение скорости биохимического окисления изученных фенолов, но не более чем на $30 \%$. В некоторых случаях (5-метилрезорцин и пирокатехин на илах, адаптированных соответственно к промышленному стоку или резорцину) процесс незначительно ускоряется или совсем не изменяется (резорцин при адаптации ила к промышленному стоку).

Из приведенного вырисовывается общая тенденция к снижению скорости окисления фенолов (не более чем на $30 \%$ от исходной величины) при вводе в систему одной из испытанных минеральных добавок, причем нанболее отчетливым образом она проявляется в случае деградации фенолов на активных илах, адаптированных к индивидуальным субстратам. Использование же ила, адаптированного к промышленному фенольному стоку, в большинстве случаев связано с некоторым ускорением процесса.

Напомним, что в активированном процессе «химического» окисления тех же фенолов, по данным [15], ввод в систему добавки хлор-ионов или тиосульфат-анионов приводит всегда к однозначным результатам. Наличие хлоридов при концентрации аниона 100 ма/л и выше, всегда стимулирует процесс окисления фенолов. Эксперимент с добавкой тиосульфат-аниона (начиная с 30 мг/л) выявляет выраженное ингибирующее ее.действие. Для полного подавления реакции окисления 5-метилрезорцина достаточна, например, весьма малая концентрация тиосульфата натрия (на уровне 100 ма/ $\Omega$ ).

В настоящем случае различная направленность в воздействии добавок хлор- и тиосульфат-анионов на систему определяется, очевидно, различной их специфической ролью в качестве средств питания микроорганизмов, развивающих активную деятельность лишь в условиях адаптации к данному субстрату. В отдельных случаях речь может идти и о проявлении тиосульфатом присущих ему восстановительных свойств с подавлением реакций окисления, как это имеет место в чисто «химических» системах. Присущая активному илу, адаптированному к промстоку, инертность к добавке указанных минеральных примесей и даже к ускорению процесса окисления в их присутствии объясняется, очевидно, 
тем, что в промышленном стоке эти добавки уже имеются и система микроорганизмов к ним устойчиво адаптирована. Однако при организации биоокислительной очистки сточных вод от фенолов следует учитывать возможность известного снижения эффективности процесса под воздействием указанных минеральных примесей, особенно в отношении разложения резорцина.

\section{Выводы}

1. Добавки хлор- и тиосульфат-иона оказывают влияние на скорость биохимического окисления фенолов. Его направленность и интенсивность определяются характером (адаптацией) активного ила и химической структурой реагента-фенола. В подавляющем большинстве случаев минеральные примеси оказывают тормозящее действие на процесс биоокисления фенолов.

2. К воздействию минеральных добавок, как правило, инертен активный ил, адаптированный к промышленному фенольному стоку, очевидно, вследствие предварительной устойчивой адаптации микроорганизмов к тем же минеральным примесям в составе стока.

\section{Л И Т Е Р А Т Р А}

1. Берновская Н., Губергриц М., Кирсо У., Изв. АН ЭССР, Хим. Геол 20,21 (1971)

2. Берновская Н., Қирсо У., Губергриц М., Изв. АН ЭССР, Хим. Геол., $20,216(1971)$

3. Берновская Н., Кирсо У., Губергриц М., Изв. АН ЭССР, Хим, Геол., $21,116(1972)$.

4. Кирсо У. Эૅ Берновская Н. А., Губергриц М. Я., Хим. тверд. топл., № 2,100 (1973).

5. Берновская Н. А., Қинетические закономерности окисления фенолов различного строения на активных илах. Диссерт. канд. хим. наук. Академия наук ЭССР, Таллин, 1973.

6. Метсик Р. Э., Исследование карбоновых кислот, сернистых и хлористых соединений при термнческой переработке эстонских сланщев, механизм их коррозионного действия и вопросы защиты аппаратуры в гланцехимической промышленности. Диссерт. докт. техн. наук. Академия наук ЭССР, Таллин, 1970.

7. Метсик Р. Э., Певкур Т. А., Рохумяги Э. И., В сб.: Добыча и перераб. горючих сланцев, вып. 18, 170 (1969), Л.

8. Лилле Ю., Кундель Х., Бюлл. Сланцев и хим. пром., № 6, 17 (1965).

9. Лилле Ю., Кундель Х., В сб.: Добыча и перераб. горючих сланцев, 16, 186 (1967), Л.

10. Ханнус М., Кирсо У., Лээсмент Л., Изв. АН ЭССР, Хим. Геол., 22, $82(1973)$.

11. Л ейдлер К., Кинетика орг. реакций, М. 1966.

12. Dagley S., Gibson D. T., Biochem. J., 95, 466 (1965).

12. Ribbon S D. W., Arch. Mikrobiol., 74, 103 (1970).

14. Neujahr H. Y., Varga J. M., Eur. J. Biochem., 13, 37 (1970).

15. Кирсо У., Берновская Н., Ханнус М., Губергриц М., Вийтма а Х., В сб.: Материалы IV Всесоюзного симпозиума по современным проблемам самоочищения и регулирования качества воды, III секция, Таллин, 1972, с. 62.

Ннститут химии

Академии наук Эстонской ССР

Таллинский политехнический институт
Поступила в редакцию 20/IV 1973 
Maila HANNUS, Uuve KIRSO

\section{MONINGATE MINERAALSETE LISANDITE MOJU FENOOLIDE BIOOKSUDEERIMISE KIIRUSELE}

Uuriti oksübensooli, resortsini, 5-metüülresortsiini ja pürokatehiini biooksüdeerimise kineetikat aktiivmudades, mis olid püsivalt adapteeritud oksübensooli, resortsiini ja tööstuslikus heitvees esinevate fenoolide segule.

Selgus, et mitmeaatomilised fenoolid lagunesid kôigis uuritud mudades, kuigi erineva kiirusega. Oksübensool lagunes ainult temaga adapteeritud mudas. Kaaliumkloriidi ja naatriumtiosulfaadi lisamine hulgal, mis vastab nende sisaldusele heitvetes, mōjutas enamikul juhtudel fenoolide lagunemiskiirust, kusjuures nende mōju ulatus ja suund sōltus nii fenooli kui ka substraadi iseloomust. Mineraalsed lisandid enamasti pidurdavad fenoolide lagunemist kuni $30 \%$. Seega vōib nende esinemine olla üheks pōhjuseks, mis vähendab bioloogilise defenoleerimise efektiivsust. Tööstuslikule heitveele adapteeritud aktiivmudas need lisandid kas suurendasid lagunemiskiirust vôi ei möjutanud seda üldse. Viimane nähtus on ilmselt tingitud mikroorganismide adapteerumisest tööstuslikus heitvees leiduvate mineraalsete lisanditega.

\section{Maila HANNUS, Uuve KIRSO}

\section{THE EFFECT OF SOME MINERAL ADMIXTURES ON THE RATE OF BIOOXYDATION OF PHENOLS}

The biooxydation kinetics of four phenols on activated sludge adapted on three substrates (oxybenzene, resorcinol and mixture of phenols in industrial wastewater) has been investigated. The decomposition of phenols on all sludges under investigation occurs fast, with the exception of oxybenzene, the decomposition of which takes place only on sludges adapted to this compound. The introduction of inorganic salts in form of kaliumchloride and sodiumthiosulphate in an amount corresponding to their content in wastewater, influences in most cases the decomposition rate of phenols. Its extent and direction depends on the character of phenols as well as on the substrate. In several cases the addition of mineral compound put a brake on the decomposition of phenols (up to $30 \%$ ); thus their existence may be considered as one of the causes of reducing the effectiveness of biological dephenolation. On activated sludges adapted to industrial wastes the mentioned mineral compounds either increase the reaction rate or do not influence it. This, obviously, is caused by the adaptation ability of microorganisms to the mineral compounds occurring in the industrial wastewater. 